\title{
Entre a Comunicação, a Política e o Espetáculo
}

\author{
Luciana Panke \\ Ricardo Philippi
}

\begin{abstract}
Resumo
Investigam-se alguns pontos de convergência conceituais entre o tripé "comunicação, política e espetáculo", revisando autores que perpassam as três áreas, principalmente aqueles que reexaminam concepções da obra Sociedade do Espetáculo, de Guy Debord (1997). São identificados esforços dos teóricos em entender o consumo, a produção e a circulação de imagens públicas, o que emparelha o conceito de espetáculo político com a estética, em especial pelas estratégias políticas midiáticas que se utilizam de afetos e emoções para a legitimação do poder. Embora este trabalho identifique o determinismo de alguns autores, observa-se também que outros pensadores buscam dialogar com o conceito, a fim de interpretar os pressupostos da Sociedade do Espetáculo na área da comunicação política.
\end{abstract}

\section{Palavras-chave:}

comunicação política, Guy Debord, sociedade do espetáculo.

\begin{abstract}
This essay investigates some points of conceptual convergence among the tripod "communication, politics and spectacle", reviewing authors that encompass these three contents, mainly those who re-examine conceptions of the Society of the Spectacle of Guy Debord (1997). The efforts of the theorists to understand the consumption, the production and the circulation of public images are identified, which parallels the concept of political spectacle with aesthetics, especially by means of media political strategies that use affections and emotions for the legitimation of power. Although this work identifies the determinism of some authors, it is also observed that other authors search for a dialogue with this concept in order to overcome determinism and interpret the assumptions of the Society of the Spectacle in the political communication area in a dialectical relation.
\end{abstract}

\section{Keywords:}

political communication, political spectacle, Guy Debord, society of the spectacle.

\footnotetext{
1 Pós-doutorado em Comunicação Política na Universidade Autônoma Metropolitana (UAMMéxico). Doutorado em Ciências da Comunicação (USP). Professora da Universidade Federal do Paraná na graduação em Publicidade e Propaganda e do Programa de Pós-Graduação em Comunicação. Líder do grupo de Pesquisa Comunicação Eleitoral. lupanke@ gmail.com

${ }^{2}$ Doutorando em Artes Cênicas, na UFBA. Mestre em Comunicação (UFPR) na linha Comunicação e Política, onde desenvolveu pesquisa referente ao Espetáculo Político. É bacharel em Relações Públicas (UFPR) e em Artes Cênicas (FAP). Integrante do Grupo de Pesquisa Comunicação Eleitoral. ricardo philippi@ hotmail.com
} 


\section{VOZES $_{\text {\&IÁLORO }}^{\mid}$}

Itajaí, v. 18, n. 01, jan/jun 2019

\section{Introdução}

Para iniciar este texto, é necessário revisar a origem da relação entre os estudos de comunicação e política, que se dividem basicamente em três grandes estágios que se intercruzam temporalmente. Segundo Gomes (2004) o primeiro estágio possui diversos estudos dispersos nos meados do século XX, analisando as propagandas políticas, opinião pública e decisão dos votos nas suas perspectivas instrumentais e dando pouca importância às lógicas imanentes da comunicação de massa, ou seja, o foco das análises são os instrumentos "de que os Estados, a sociedade ou os particulares lançariam mão para produzir um certo efeito ou realizar uma determinada função” (GOMES, 2004, p. 18). Esses se correlacionam principalmente às teorias hipodérmicas norte-americanas, que se ancoram na visão da sociedade de massa e industrial do século $\mathrm{XX}$, "onde os indivíduos estão isolados física e psicologicamente [...], e nas teorias behavioristas (Watson) que entendiam a ação humana como resposta a um estímulo externo" (ARAUJO, 2003, p. 125).

Num segundo estágio, que permeia a segunda metade do século XX até o início do novo milênio, temos as primeiras grandes teorias a respeito da comunicação política, correlacionando a comunicação de massa e a indústria cultural como centro da cena das instituições sociais. Entretanto, esse momento herda da fase anterior as análises "desconfiadas” da relação entre comunicação e política, podendo ser qualificadas, segundo Gomes (2004, p. 21), como apocalípticas, dentro da dicotomia proposta por Umberto Eco. Essas perspectivas são oriundas da teoria crítica, cujo "estudo sobre os mass media que não seja capaz de se aperceber da estrutura multiestratificada e, acima de tudo, dos efeitos das mensagens ocultas, coloca-se numa perspectiva limitada e desviante” (WOLF, 2003, p. 90). Gomes (2004, p. 22) afirma que estes trabalhos aumentaram exponencialmente em volume de produções nas décadas de 80 e 90 , "quando certamente se publicou muito mais sobre comunicação e política que nos setenta anos precedentes”.

Publicações essas que continuaram crescendo em quantidade de produções nos anos subsequentes até o momento atual, culminando no terceiro estágio de estudos que vão se associando à interdisciplinaridade. Destacam-se o surgimento das diversas especialidades com inúmeros objetos de análise, por exemplo: estudos de gênero nas campanhas políticas; jornalismo da esquerda política; comunicação política em diversas regiões do mundo, entre muitas outras. É evidente "a velocidade com que um modelo de interface entre as esferas da comunicação de massa e da política se estabeleceu e se espalhou pelo mundo nas últimas três, no máximo quatro décadas” (GOMES, 2004, p. 23). 


\section{Comunicação, política e espetáculo}

Assim, no atual estágio de estudos, acentuam-se as pesquisas que buscam investigar as habilidades, características e competências dos inúmeros atores envolvidos nas relações entre a política e a comunicação. Os principais fundamentos que se destacam em relação ao espetáculo são os conceitos que analisam a construção e manutenção da imagem política, vórtice das hodiernas estratégias de legitimação do poder. Weber (2004) nos auxilia a entender esse assunto, quando comenta que a imagem é algo que está detido entre a realidade e, no caso da política, da representação das opiniões. A autora compreende que a comunicação política também é cenário de disputas pela imagem pública, ou seja, pelo simulacro, mimese, indivíduos, sociedade, onde os sujeitos políticos falam, buscam e disputam opiniões:

A visibilidade cobiçada por sujeitos políticos é mantida por uma cadeia de insumos tangíveis, no campo visual, sonoro e sensitivo, que vão formando identificações visuais a serem associadas a informações abstratas de origem incontrolada, pertencentes ao acervo de fragmentos depositados no imaginário individual e hierarquizados pela paixão, pela história, cultura e ideologia de cada um (WEBER, 2004, p. 265).

Por consequência da construção e manutenção dessas representações, há estudos deste terceiro estágio que buscam investigar novas estratégias de visibilidade para a manutenção do poder criadas na cultura política que, segundo afirma Gomes (2004, p. 24), são centradas na ideia de consumo, produção e circulação de imagens públicas. Conforme o autor, para que sejam eficientes, elas necessitam de competências técnicas, tais como sondagem de opinião, assessoria, marketing, consultoria de imagem, ou seja, das habilidades e métodos oriundos de um trabalho de comunicação. Nesse sentido, Almeida (2004, p.329) comenta que uma personalidade política, partido ou aliança que pretende ter uma longa vida pública precisa pensar tal como uma "marca”, ou seja, adotar estratégias semelhantes ao do "marketing de relacionamento", criando lealdade à "marca" a partir de reconhecimento, aceitação e preferência política.

Por isto, neste cenário, há a dependência dos atores da utilização das gramáticas específicas e de acordo com o meio onde devem circular suas opiniões, tal qual exige o audiovisual, com fórmulas de exibição e narração oriundas do universo do entretenimento. Segundo Gomes (2004, p. 25), é fato que as estratégias dominantes na política atual estão vinculadas ao entendimento de que as audiências devem ser convertidas em eleitores ou opinião pública favorável ao ator político. É desta particularidade da comunicação política que decorrem as estratégias midiáticas que evidentemente se utilizam de afetos e emoções, convertendo ideias em narrativas espetaculares, incomuns e/ou escandalosas, se emparelhando à estética. 


\title{
VOZES! \\ DIÁLOGO
}

Itajaí, v. 18, n. 01, jan/jun 2019

Essa relação é discutida por Rancière (2005, p. 59), a exemplo da citação: "a política e a arte, tanto quanto os saberes, constroem 'ficções', isto é, rearranjos materiais dos signos e das imagens, das relações entre o que se vê e o que se diz, entre o que se faz e o que se pode fazer". Assim, tal plasticidade política pode se apresentar sob novas subjetividades, ideias e conceitos, exercendo até mesmo um papel pioneiro às abstrações, como explicita o autor:

\begin{abstract}
A noção de vanguarda define o tipo de tema que convém à visão modernista e própria a conectar [...] o estético e o político. Seu sucesso está menos na conexão cômoda que produz entre a ideia artística da novidade e a ideia da direção política do movimento, do que na conexão mais secreta que opera entre duas ideias de "vanguarda”. Existe a noção topográfica e militar da força que marcha à frente, que detém a inteligência do movimento, concentra suas forças determina o sentido da evolução histórica e escolhe as orientações políticas subjetivas. Enfim, há essa ideia que liga a subjetividade política a uma determinada forma - do partido, do destacamento avançado extraindo sua capacidade dirigente de sua capacidade para ler e interpretar os signos da história. E há essa outra ideia de vanguarda que se enraíza na antecipação estética do futuro. (RANCIÈRE, 2005, p. 43)
\end{abstract}

Esse conteúdo estético político é o atributo que se funde em uma única ideia que complementa os estudos entre comunicação e política: o espetáculo. Rubim (2004, p. 194) comenta que a etimologia dessa palavra é spetaculum, cujo significado semântico remete a tudo aquilo que atrai a visão e se revela aos sentidos. O autor aponta que o dicionário ainda traz outras acepções, como representação teatral, exibição esportiva/artística, além de cenas ridículas ou escandalosas. Em suma, os significados desse termo "implicam uma visão atenta a uma circunstância, uma relação entre espectador e evento, que chama a atenção e prende o olhar" (RUBIM, 2004, p. 192).

\section{Heranças do determinismo debordiano}

Um dos primeiros teóricos a se debruçar sobre esse tema em profundidade em seu âmbito social e moderno é o francês Guy Debord, ressignificando o conceito em seu livro Sociedade do Espetáculo, editado pela primeira vez em 1967. Suas ideias são basicamente balizadas no julgamento negativo, muitas vezes feito com conotação de manifesto, frente à comunicação de massa ${ }^{3}$. Tema fulcral do pensamento debordiano é o impacto da presença do espetáculo na vida das pessoas, gerando passividade e aceitação do sistema dominante imposto pela ordem midiática. $\mathrm{O}$ autor comenta que:

\footnotetext{
${ }^{3}$ Esse exemplar foi também uma das principais inspirações do movimento contestatório de maio de 1968 em Paris. Movimento esse de greve geral ocorrido na França naquele ano, com características revolucionárias organizadas principalmente por grupos adeptos do anarquismo e comunismo.
} 


\title{
VOZES $_{\text {\&IÁLORO }}^{\mid}$
}

Itajaí, v. 18, n. 01, jan/jun 2019

\begin{abstract}
A alienação do espectador em favor do objeto contemplado (o que resulta de sua própria atividade inconsciente) se expressa assim: quanto mais aceita reconhecer-se nas imagens dominantes da necessidade, menos compreende sua própria existência e seu próprio desejo. Em relação ao homem que age, a exterioridade do espetáculo aparece no fato de seus próprios gestos já não serem seus, mas de um outro que os representa por ele. É por isso que o espectador não se sente em casa em lugar algum, pois o espetáculo está em toda parte. (Grifo nosso, DEBORD, 1997, p. 24).
\end{abstract}

Essa passividade do espectador é presente desde a primeira tese de seu livro: "toda a vida das sociedades nas quais reinam as modernas condições de produção se apresenta como uma imensa acumulação de espetáculos. Tudo o que era vivido diretamente tornouse representação" (Grifo do autor, DEBORD, 1997, p.13). Eis a separação consumada que balizará todas as asserções de Debord: o espetáculo separaria a imagem daquilo que é a realidade.

Pelo seu forte determinismo, algumas das suas perspectivas já são consideradas ultrapassadas, a exemplo da passagem de Rubim (2004, p. 184): "Além da flutuação conceitual, natural em uma obra-manifesto, a construção de Debord encontra-se prejudicada, pois atribui ao espetáculo, como dispositivo imanente, uma conotação sempre negativa”. Debord, assim, se atrela ao segundo estágio dos estudos da comunicação política pela sua visão "desconfiada" dos meios de comunicação de massa, entretanto, suas deduções não eliminam suas colocações na contemporaneidade, principalmente pelo fato inevitável de obrigar os pesquisadores a dialogar com seus preceitos. Carvalho (2015, p.129), explica que o conceito "sociedade do espetáculo" é histórico-crítico, o que lhe convém em um ambiente dialético, ou seja, não invalida de maneira nenhuma os preceitos do autor francês no quadro hermenêutico da época contemporânea, pois é impossível de se contornar tal preceito teórico ao abordar o tema.

Desse modo, seus críticos o classificam como um clássico, o que torna seus escritos atemporais e sujeitos a exames sempre possíveis à luz dos paradigmas vigentes, até mesmo na negação do seu pensamento. Novamente Rubim (2004, p. 184) comenta que as formulações que vislumbram os movimentos do moderno irão constituir, "sem dúvida, um dos pontos de destaque da obra de Guy Debord e reafirma a atualidade de suas reflexões. Isto não pode significar, no entanto, a aceitação integral, sem mais, de sua elaboração teórica”.

Este autor ressalta que um dos eixos da obra do pensador francês a se meditar, é, como já comentado acima, a ruptura entre o real e a imagem que ocorre na sociedade do espetáculo:

Tal cisão, consumada na contemporaneidade, inaugura a possibilidade da sociedade do espetáculo. Nela, as imagens passam a ter lugar privilegiado no âmbito das representações. Nas palavras de Debord, “o 


\section{VOZES $_{\text {\&IÁLORO }}^{\mid}$}

Itajaí, v. 18, n. 01, jan/jun 2019

espetáculo, como tendência a fazer ver (por diferentes mediações especializadas) o mundo que já não se pode tocar diretamente, serve-se da visão como sentido privilegiado da pessoa humana" (DEBORD, 1997, p. 18). Entretanto, "o espetáculo não é um conjunto de imagens, mas uma relação social entre pessoas, mediada por imagens" (DEBORD, 1997, p. 14). A emergência de uma sociedade do espetáculo depende, assim, desta "separação consumada", mas requer uma outra condição: a autonomização da representação frente ao real. "Sempre que haja representação independente, o espetáculo se reconstitui” (DEBORD, 1997, p. 18). (RUBIM, 2004, p. 184)

Desta forma, a autonomização do real frente ao espetáculo político-midiático, baseado no aceite da lógica debordiana, teria como consequência a despolitização das imagens públicas e dos atores políticos, que não se vinculariam mais diretamente à realidade, uma vez que a imagem se tornaria a mediação das relações que se configurariam como, consequentemente, ilusórias. $\mathrm{O}$ importante neste momento é ressaltar o determinismo defendido por Debord gerado pelas imagens da sociedade do espetáculo:

A consciência espectadora, prisioneira de um universo achatado, limitado pela tela do espetáculo, para trás da qual sua própria vida foi deportada, só conhece os interlocutores fictícios que a entretêm unilateralmente com sua mercadoria e com a política de sua mercadoria. O espetáculo, em toda a extensão, é sua "imagem do espelho". Aqui se encena a falsa saída de um autismo generalizado. (DEBORD, 1997, p. 140)

Consequentemente, para os pensadores que concordam com os preceitos debordianos, como Schwartzenberg (1977, p. 146), a política se tornaria uma extensão de um gênero narrativo, com características do tratado da representação aristotélica e com a alienação dos indivíduos envolvidos. Para ele, são evidentes até mesmo personagens, tramas e falas, a exemplo dos inúmeros espetáculos de políticos que exibem suas paixões, servindo-se até como catarse, de tal forma que os cidadãos tornam-se espectadores “convidados a 'purgar suas paixões' por ato interposto”. Assim, o indivíduo identifica-se com seu herói político através de suas ditas e desditas e, consequentemente, a representação política alienaria o cidadão que é vivido por procuração, ou seja, "outros vivem em seu lugar os acontecimentos que ele não tem tempo ou recursos para viver. $\mathrm{O}$ espectador do herói não vive realmente: ele é 'vivido"”.

Além disto, seria possível identificar papéis típicos aplicados aos atores políticos, tais como: o herói, o líder-charmoso, o pai, o salvador da pátria, o inimigo do povo, a lady de ferro, a mulher mãe, o self-mademan, o empresário, o intelectual, o religioso, o candidato "genérico", o tradicional, o homem do campo, o sindicalista, o trabalhador, o atleta e artista, entre diversos outros (ITEN, 2002; SCHWARTZENBERG, 


\section{VOZES $_{\text {\&IÁLORO }}^{\mid}$}

Itajaí, v. 18, n. 01, jan/jun 2019

$1977)^{4}$. O político, neste entendimento, estaria também agrilhoado à extensão de sua própria personagem, e deve interpretar de maneira duradoura a persona em cuja pele se meteu, "precisa aceitar ajustar-se à imagem de si mesmo divulgada pela propaganda. Assim vive ele, aprisionado num papel determinado, como um ator, e escravo de seu próprio mito.” (Grifo nosso, SCHWARTZENBERG, 1977, p.14). É o que Weber (2004) argumenta serem as máscaras públicas, atreladas ao fazer política do espetáculo.

Ainda para Schwartzenberg (1977) a política midiatizada se tornaria um teatro de ilusões, com o objetivo de enganar e distrair os espectadores, fazendo-os contemplar as emoções fictícias e egocêntricas dos atores políticos, ao invés de refletir sobre os reais problemas sociais. $\mathrm{O}$ que podemos inferir no caso de uma política não mediatizada? O teatro político cessaria? No caso de uma política não mediatizada, a tendência é seguir coerentemente com a imagem pública divulgada midiaticamente, evitando distorções.

Tal determinismo decorrente do segundo estágio dos estudos de comunicação política ecoa também em Ribeiro (1994, p. 34) quando argumenta: “Quanto mais se teatralizar a política - quanto mais os cidadãos forem reduzidos a público, a espectadores das decisões políticas, menor será o caráter público das políticas adotadas, menor seu compromisso com o bem comum”. Para este autor, aquilo que exigiria um debate racional da política é transferido para as emoções espetacularizadas, perdendo sua real importância nos debates democráticos, de forma que ou nos rebaixamos ao estado bruto em que a força da linguagem resolve as situações; ou nos alçamos ao divino, tal qual a figura de um herói mitológico, semelhante a um semideus que tem poderes para resolver nossos problemas que são vistos de forma tão complexa que somente uma intervenção ex machina ${ }^{5}$ poderia trazer uma solução imediata (RIBEIRO, 1994, p. 35).

É possível também distinguir esse determinismo em Amaral (2000, p. 158, apud NUNES, 2004, p. 361) quando aponta que a política midiatizada esvazia-se de suas reais funções instrumentais de realizar fins sociais e, ao invés disto, objetiva ambições ulteriores, desde a fraude até a traição dos interesses coletivos, tal qual a arte da mentira. Para esse autor, uma vez que a política se torna simulacro da política, sem um real diálogo ou representação, a própria liberdade de imprensa seria o manto que encobre o contraditório e o confronto de ideias, e consequentemente a cidadania seria o engodo desta ilusão. O autor (2000), ao criticar a política espetáculo, no que ele chama de vídeo show (na imagem em sua forma televisiva), argumenta que o debate racional se torna o excedente, pois, “conflito de lógica antípodas, a televisão limpa a política de seu conteúdo,

\footnotetext{
${ }^{4}$ Dentre esses vários papéis, será objeto de estudo e análise deste trabalho o do palhaço político que não está incluído nesta lista apresentada pelos autores.

${ }^{5}$ Mecanismo dramatúrgico utilizado em enredos que se tornam tão complicados que a única solução é o aparecimento súbito de uma divindade que soluciona a trama, comum no teatro grego de Ésquilo (IV-V a.C.) e Sófocles (V a.C.).
} 


\section{VOZES

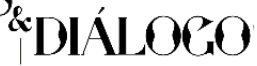

Itajaí, v. 18, n. 01, jan/jun 2019

e trata de transformá-la em espetáculo. Fantástico, se possível” (AMARAL, 2000, p. 159, apud NUNES, 2004, p. 361).

Ademais, é implícito na fala desses autores, que o próprio político se tornaria uma marionete de interesses outros, como o intérprete sob direção cinematográfica, o ator manipulado pelos produtores e coordenadores de mídia e pelos interesses dos grupos de pressão, como partidos e financiadores. "A vedete (do cinema e da política) vem a ser uma criação de apresentadores de fantoches” (SCHWARTZENBERG, 1977, p. 158).

Esse distanciamento da imagem com o real é criticado também por Courtine (2003) que aponta o paradoxo criado entre o cidadão e o orador político nos tempos dos meios de comunicação de massa e tecnologias audiovisuais, gerando o que ele chamou de proximidade longínqua, por dois fatores: o primeiro pelo ocultamento da tecnologia por detrás das imagens, e o segundo pelo olhar do espectador que se aproximou do sujeito político, porém nas suas aparências: "E os políticos, oscilariam, a partir daí, entre heróis de novela e mercadorias à venda, teriam um papel incerto. Em suma, seria o fim do político” (p. 30).

\section{No rumo de um novo entendimento}

O pessimismo inaugurado nas teses de Debord, e enfatizado suas ramificações, tornou-se hegemônico nos estudos correlacionados ao espetáculo político midiático, uma vez que "a maioria avassaladora dos trabalhos, internacionais ou nacionais, inscreve-se, consciente ou inconsciente, neste modelo analítico, (...) com menor ou maior sofisticação" (RUBIM, 2004, p. 188). Assim, o livro Sociedade do Espetáculo torna-se "um texto que na área da comunicação política tem sido mais referido e citado do que explicado e interpretado" (GOMES, 2004, p. 399).

Por esse motivo, neste trabalho há a preocupação de desviar-se de tal determinismo como único modo possível de pensamento que embasa o tripé comunicação, política e espetáculo. Gomes (2004, p. 419) argumenta que tais teorias políticas cegam-se diante das transformações da sociedade contemporânea, não se beneficiando da interdisciplinaridade dos estudos oriundos da comunicação e da política, entretanto, na sua concepção, este campo também está maduro o suficiente para superar tal perspectiva.

Para isto, deve ser levado em consideração que não há como imaginar uma sociedade com "grau zero" de teatralização do poder, pois é impossível a interação entre os indivíduos sem a representação de papéis, ou seja, é impossível pensar uma formação social que dispense a dramaturgia política (GOMES, 2004, p. 416). A própria origem da representação cênica surge da necessidade do homem em se auto avaliar, ou melhor, "o teatro nasce quando o ser humano descobre que pode observar-se a si mesmo: ver-se em ação. Descobre que pode ver-se no ato de ver - ver-se em situação” (BOAL, 1996, p. 27). 


\section{VOZES $_{\text {\&IÁLORO }}^{\mid}$}

Itajaí, v. 18, n. 01, jan/jun 2019

Aliado a este conceito, o surgimento da oratória e a política com base na Grécia antiga também privilegiava a encenação como parte importante na manutenção da atenção da plateia. A política é feita não apenas dos debates racionais ou técnicos, mas possui, em suas instâncias, elementos emocionais que carregam em si as suas disputas de valores e de representações: "Sem a emotividade que sempre carrega, a política perderia a maior parte de seu fascínio e atração” (MIGUEL, 1998, p. 6).

Assim, para responder a uma problemática apresentada pela espetacularização da política em um mundo estruturado em rede e ambientado pela mídia, não se pode deixar de "reconhecer o recurso à emoção, à sensibilidade, à encenação, aos ritos e rituais, aos sentimentos, aos formatos sociais, aos espetáculos" (RUBIM, 2004, p. 191) como algo natural e inerente ao cenário político de qualquer tempo. Além do mais, a legitimação das conquistas e da manutenção do poder perpassam pelo tema do espetáculo, que:

[...] passa a ser produzido também como modo de sensibilização, visando a disputa do poder, e como construtor de legitimidade política. As articulações entre o espetáculo e o poder político ou a política mostram assim distinções relevantes.

O espetáculo, portanto, não aparece como estranho à política, apesar do deslocamento acontecido. O estranhamento só aflora quando se trabalha com uma concepção unilateral, redutora e simplista da política, concebida como atividade orientada apenas por sua dimensão argumentativa. Tal visão racionalista da política não se sustenta nem factual, nem normativamente. Para a política, entendida como acionamento sempre combinado e desigual de dimensões emocionais, cognitivas e valorativas, estéticas e argumentativas, o espetáculo aparece como uma possibilidade de realização, dentre outras em cena. (RUBIM, 2004, p. 189 e 190)

Pode-se afirmar, também, que essa encenação é clara nas organizações e práticas sociais, uma vez que sua ação se correlaciona às máscaras sociais, ritos e imaginários coletivos; algo presente desde os primórdios do poder político (RUBIM, 2004, p.182). O espetáculo torna-se assim algo inerente à sensibilidade política, principalmente pela identificação dos atores envolvidos tanto nas emoções, quanto nas razões expostas.

Em paralelo a isto, Panke (2010) argumenta, interpretando Rancière, que a política também é amparada na estética, e nem por isto se deprecia, afinal "uma estética atraente poderia ser uma forma de atrair quem não tem interesse nas questões políticas” (p. 15). Assim sendo, uma "emancipação" política dos cidadãos também estaria relacionada à estética, pois:

A multiplicação dos discursos denunciando a crise da arte ou sua captação fatal pelo discurso, a generalização do espetáculo ou a morte da imagem são indicações suficientes de que, hoje em dia, é no terreno estético que prossegue uma batalha ontem centrada nas promessas da 


\section{VOZES $_{\text {\&IÁLORO }}^{\mid}$}

Itajaí, v. 18, n. 01, jan/jun 2019

emancipação e nas ilusões e desilusões da história. (RANCIÈRE, 2010, p. 11)

Disto infere-se que o espetáculo político se aproxima da democracia porque daria "acessibilidade estética” aos debates públicos, além de tornar agradável aos olhos do público temas de interesse à cena pública. Miguel (2010a, p. 12) tece a observação de que, do ponto de vista prático, há o progresso democrático na desmistificação dos líderes políticos a partir da "superabundância" de informações que a exposição cotidiana instaura sobre as figuras públicas e que, mesmo que entenda que há certa banalização das opiniões, nunca houve na história nada parecido com os debates contemporâneos das ideias.

Consequentemente, para se destacar nos debates do espetáculo do poder, os políticos buscam adotar práticas para gerir sua exposição, tal qual comenta Miguel, quando se refere às alterações das práticas políticas com o advento das diversas mídias, uma vez que "a visibilidade da mídia é, cada vez mais, componente da produção do capital político. (...) A notoriedade midiática é condição necessária para o acesso às posições mais importantes do campo político” (MIGUEL, 2010a, p. 10). Além do mais, diferentemente do que ocorria no passado, as elites políticas devem cuidar de sua "retaguarda", ou seja, de sua vida privada, sendo a gestão de escândalos um componente cotidiano de seu trabalho público. Por esses e outros fatores, o autor acima referenciado reconhece que a mídia se tornou o fator central da política contemporânea e, além do mais, é impossível se mudar tal fato.

Doravante, o conceito de espetáculo político ganha atributos de uma estratégia política para obtenção da percepção do cidadão sobre questões de interesses públicos, como sintetiza Gomes (2004):

\footnotetext{
A meu ver, o único ponto em comum na dispersão das várias metáforas [a respeito do conceito de espetáculo político] é a ideia de exibição, de exposição, que se condensa metaforicamente na ideia de cena. Isso quer dizer, em suma, que a política-espetáculo é a política em cena, a política naquilo que nela se destina a se apresentar a uma plateia ou a um público. Para evitar que fiquemos explicando uma metáfora por outra, gostaria de sugerir que a política-espetáculo é a política que emprega a sua presença na esfera de visibilidade pública como estratégia para a obtenção do apoio ou do consentimento dos cidadãos. A política-espetáculo é a política que se exibe, mostra-se, faz-se presença, impõe-se à percepção do cidadão. (Grifo nosso, GOMES, 2004, p. 403)
}

Nesse sentido, a partir dessa última conceituação, é possível deduzir que uma sociedade democrática depende também da percepção do cidadão das discussões públicas para, consequentemente, influenciar as decisões políticas. A diferença é que na atualidade participam deste "jogo" novas estratégias de exposições (como a memecracia, as notícias 


\section{VOZES

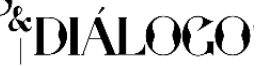

Itajaí, v. 18, n. 01, jan/jun 2019

falsas), chegam mais atores políticos, especialmente nas redes sociais digitais. Logo, para esses autores do terceiro estágio, quanto mais elevado o caráter espetacular da política, aumenta também a exposição das coisas públicas e pode aumentar a chance de percepção política dos cidadãos nos embates políticos. Ou seja, segundo Gomes (2004, p 403), “a política-espetáculo é um dispositivo da política tout court, uma etapa, aparentemente necessária”, de forma a desejar o cidadão como espectador, todavia, não o quer definitivamente como um assistente. Afinal "a reunião do público numa audiência é apenas a condição imediata para que alcance o seu propósito para se transformar em um agente político na decisão do voto, na manifestação de rua, no oferecimento de apoio ou da força do número" (Ibidem).

Nesse entendimento, ainda há o cidadão espectador, porém, aqui ele não é mais compreendido unicamente de modo passivo como visto por Debord, pelo contrário, o espetáculo auxilia na promoção dos diversos espaços democráticos, pois expõe e articula possibilidades de acesso à política e à coisa pública, uma vez que a exposição amplia a possibilidade do cidadão legitimar e participar do jogo democrático. Conserva-se, assim, a capacidade de formar opinião sobre a esfera pública mesmo que ela tenha se tornado midiática e, ainda numa lógica do entretenimento, é possível separar posições distintas oriundas da cena política (GOMES, 2008, p. 132).

Afinal se, por um lado, há um reducionismo em crer na alienação como único resultado possível da convergência do tripé comunicação, política e espetáculo e com um ator político alienado frente ao espetáculo midiático; no movimento oposto, há uma concepção mais interligada às transformações naturais da sociedade, que considera o espetáculo apenas como estratégia usada na comunicação política a fim de influenciar a esfera pública, utilizando-se das emoções e dos afetos da estética no exercício do poder, tal qual em seus primórdios: "Anteriormente ao surgimento da política na Grécia antiga [...] já o espetáculo estava estreitamente ligado ao exercício do poder político" (RUBIM, 2004, p. 189).

\section{Considerações Finais}

Comunicação, espetáculo e política são áreas que se intercruzam, atuando conjuntamente. Para a política ser palatável à população, acaba-se percebendo a produção discursiva centrada em uma estética comunicativa que faça com que a ação chegue ao cidadão comum.

Se por um lado, o espetáculo político esteve relacionado ao determinismo que limitaria a atuação do eleitorado como mero assistente de um mundo manipulador e que subestima a capacidade de julgamento das pessoas, por outro, há o grupo que entende o espetáculo como uma forma de expor didaticamente conteúdos políticos. 


\section{VOZES $_{\text {\&IÁLORO }}^{\mid}$}

Itajaí, v. 18, n. 01, jan/jun 2019

Os estudos frutos do espetáculo político-midiático se encontram em constantes mutações, por isso é necessário compreender seus fluxos e deslocamentos, a fim de dominar seus diversos processos para o fortalecimento do pensamento democrático. Deste modo, resquícios do determinismo, fruto do pensamento do espetáculo debordiano estão sendo superados no terceiro estágio dos estudos entre a comunicação e a política.

É importante ter em mente que a política está presente no cotidiano das pessoas, sem que, muitas vezes, elas tenham consciência disso. Portanto, o uso de uma linguagem apropriada nas ações de comunicação política poderia ser facilitadora não apenas para o entendimento, mas também para a participação política popular.

\section{Referências}

ALMEIDA, Jorge. O Marketing Político-eleitoral. In: RUBIN, Antonio Albino Canelas. Comunicação e Política: conceitos e abordagens. Salvador - BH: Edufba, 2004.

BOAL, Augusto. $\mathrm{O}$ arco-íris do desejo: $\mathrm{O}$ método Boal de teatro e terapia. Rio de Janeiro: Civilização Brasileira, 1996.

CARVALHO, Eurico. A ideia de espetáculo: crítica e sistema em Guy Debord. Aufkärung, v.2, n.1, Abril de 2015.

DEBORD, Guy. A sociedade do espetáculo: comentários sobre a sociedade do espetáculo. Tradução Estela dos Santos Abreu. Rio de Janeiro: Contraponto, 1997.

GOMES, Wilson. Transformações da política na era da comunicação de massa. São Paulo, São Paulo: Paulus, 2004.

ITEN, Marco; KOBAYASHI, Sérgio. Eleições: vença a sua! As boas técnicas de marketing. São Paulo: Ateliê, 2002.

MARQUES, Jamil. A ideia de democracia em perspectiva. Crise, abraços e desafios. Liberdade e Cidadania, Brasilia-DF, ano II, n. 5, jun/set. de 2009.

MIGUEL, L. Felipe. Em torno do conceito de mito político. Dados, v. 41, n. 3, Rio de Janeiro, 1998.

Mito e discurso político: uma análise a partir da campanha eleitoral de 1994. São Paulo: Unicamp, 2000.

NUNES, Márcia Vidal. Mídia e eleição. In: RUBIN, Antonio Albino Canelas. Comunicação e Política: Conceitos e abordagens. Salvador - Belo Horizonte: Edufba, 2004 .

PANKE, Luciana. Política e entretenimento: cruzamento e/ou interferência na construção de sentidos. Animus (Santa Maria), v. 18, p. 13-30, 2010.

RANCIÈRE, Jacques. A partilha do sensível: Estética e Política. São Paulo: Exo Experimental, 2005.

El espectador emancipado. Buenos Aires: Manantial; 2010 . 


\section{VOZES $_{\text {\&DÁLORO }}^{\mid}$}

Itajaí, v. 18, n. 01, jan/jun 2019

RIBEIRO, J. Renato. A política como espetáculo. In: Os anos 90: política e sociedade no Brasil / org. Evelina Danino. São Paulo: Brasiliense, 1994.

RUBIN, Antonio Albino Canelas. Espetacularização e Midiatização da Política. In: RUBIN, Antonio Albino Canelas. Comunicação e Política: Conceitos e abordagens. Salvador - BH: Edufba, 2004.

SCHWARTZENBERG, Roger-Gérard. O Estado espetáculo. São Paulo: Círculo do Livro, 1977.

WEBER, Maria Helena. Imagem Pública.In: RUBIN, Antonio Albino Canelas. Comunicação e Política:conceitos e abordagens. Salvador - Belo Horizonte: Edufba, 2004.

WOLF, Mauro. Teorias das comunicações de massa. São Paulo: Martins Fontes, 2003. 